\title{
Biosynthesis of silver nanoparticles using aqueous leaf extract of Thevetia peruviana Juss and its antimicrobial activities
}

\author{
Omolara O. Oluwaniyi ${ }^{1} \cdot$ Haleemat I. Adegoke ${ }^{2}$. \\ Elijah T. Adesuji ${ }^{3} \cdot$ Aderemi B. Alabi $^{4} \cdot$ Sunday O. Bodede ${ }^{5}$. \\ Ayomide H. Labulo ${ }^{3}$. Charles O. Oseghale ${ }^{3}$
}

Received: 10 July 2015/ Accepted: 5 October 2015/Published online: 19 October 2015

(C) The Author(s) 2015. This article is published with open access at Springerlink.com

\begin{abstract}
Biosynthesizing of silver nanoparticles using microorganisms or various plant parts have proven more environmental friendly, cost-effective, energy saving and reproducible when compared to chemical and physical methods. This investigation demonstrated the plant-mediated synthesis of silver nanoparticles using the aqueous leaf extract of Thevetia peruviana. UV-Visible spectrophotometer was used to measure the surface plasmon resonance of the nanoparticles at $460 \mathrm{~nm}$. Fourier Transform Infrared showed that the glycosidic - $\mathrm{OH}$ and carbonyl functional group present in extract were responsible for the reduction and stabilization of the silver nanoparticles. $\mathrm{X}$ ray diffraction, Scanning Electron Microscopy, Transmission Electron Microscopy and Selected Area Electron Diffraction analyses were used to confirm the nature, morphology and shape of the nanoparticles. The silver nanoparticles are spherical in shape with average size of $18.1 \mathrm{~nm}$. The synthesized silver nanoparticles showed activity against fungal pathogens and bacteria. The zone of inhibition observed in the antimicrobial study ranged between 10 and $20 \mathrm{~mm}$.
\end{abstract}

Elijah T. Adesuji

turpsyelikay20@yahoo.com; eelijah20@gmail.com

1 Department of Industrial Chemistry, University of Ilorin, Ilorin, Nigeria

2 Department of Chemistry, University of Ilorin, Ilorin, Nigeria

3 Department of Chemistry, Federal University Lafia, Lafia, Nigeria

4 Department of Physics, University of Ilorin, Ilorin, Nigeria

5 School of Chemistry, University of KwaZulu-Natal, Westville Campus, Durban, South Africa
Keywords Silver nanoparticles - Biosynthesis ·

Optimization - Antimicrobial activity $\cdot$ Thevetia peruviana

\section{Introduction}

Nanoparticles have been the subject of substantial research in recent years. It has been explored by researchers in various fields of science and technology (Kholoud et al. 2010). The nature and unique properties observed in metal nanoparticles in the area of electronics, optics, organic catalysis, medical applications, vector control, sensor, etc., have drawn extensive attention to this field of study (Mousavand et al. 2007). Metallic nanoparticles can absorb electromagnetic radiation, resulting in surface plasmon polaritons at the metal dielectric interface (Haoyan and Hergen 2009). Surface plasmons are defined as the collective oscillation of electrons in the valence band of metal (Peter et al. 2010). The resonance wavelength of metallic nanoparticles is strongly dependent on the metal, the particle size and the particle shape (Xia and Halas 2005). One of the most useful, formulated, and valuable noble metal nanoparticles is silver nanoparticles.

Silver nanoparticles are mostly smaller than $100 \mathrm{~nm}$ and consist about 20-15,000 silver atoms. In its nanoscale form, silver exhibits unique physicochemical and biological activities. This has made them useful as sensor, vector control, antimicrobial, anticancer, and antiplasmodial agents, catalysts, among others (Elemike et al. 2014; Ashokkumar et al. 2013; Vinod et al. 2014; Ravi et al. 2013; Kathiravan et al. 2014; Raju et al. 2012; Saraschandra and Sivakumar 2014; Rajakumar and Abdul Rahuman 2011; Namita and Soam 2014). Biological/green method of synthesizing silver nanoparticles uses various plants, plant parts or microorganisms to reduce silver ion to 
silver nanoparticles. Green method using naturally occurring precursors such as vitamins, sugars, plant extracts, biodegradable polymers and microorganisms as reductants and capping agents are more environmental friendly and effective (Jitendra et al. 2014). This method is simple, costeffective, energy-saving and reproducible. Few of the plants and plant parts that have been reported in synthesizing silver nanoparticles are pineapple leaf (Elemike et al. 2014), lemongrass (Cymbopogon flexuosus), Datura metel flower (Chandran et al. 2012), Thevetia peruviana latex (Rupiasih et al. 2013), Wrightia tinctoria (Bharani et al. 2011), Solanum xanthocarpum (Muhammad et al. 2012), Opuntia ficus (Silva-de-Hoyos et al. 2012), Sphaeranthus amaranthoides (Swarnalatha et al. 2012), Punica granatum (Naheed et al. 2012) Citrullus colocynthis (Satyavani et al. 2011), switchgrass (Cynthia et al. 2012), Eucalyptus chapmaniana (Ghassan et al. 2013), Acacia auriculiformis (Nalawade et al. 2014), Ficus benghalensis, Azadirachta indica (Debasis et al. 2015), etc. The biomolecules present in these plants are responsible for the formation and stabilization of silver nanoparticles (Iravani et al. 2014).

Thevetia peruviana, otherwise known as the bush milk, be-still tree, lucky nut or yellow oleander, is an evergreen ornamental, dicotyledonous shrub. It belongs to the Apocyanaceae family (Dutta 1964). The plant is native to Central and South America. It is frequently grown throughout the tropical and sub-tropical region of the world. In Nigeria, T. peruviana has been grown for over 50 years as an ornamental plant in homes, schools and churches by missionaries and explorers. The flowers and fruits of $T$. peruviana are available all the year round, thereby providing a steady supply of seeds. No part of the plant has been reported as being used for food (Ibiyemi et al. 2002). T. peruviana seed contains toxic compounds which are mostly cardiac glycosides and their free aglycones such as thevetin, theveridoside, theveside, cerberin, peruvoside, perusitin and digitoxigenin (Oluwaniyi and Samuel 2007). The fresh flowers of T. peruviana have been reported to contain quercetin, kaempferol and quercetin 7-o-galactoside (polyphenols). The presence of flavonol glycosides, phenols and proteins in the leaf extract have been reported (Mathuravalli and Eswara 2012; Supinya et al. 2002).

However, T. peruviana latex has been used for the biosynthesis of silver nanoparticles; the use of aqueous leaf extract of $T$. peruviana reported in this paper is the first to the best of our knowledge in the synthesis and applications of silver nanoparticles. In this report, we explored the effectiveness of $T$. peruviana aqueous leaf extract as a viable source of reducing and stabilizing agent for silver nanoparticles. The antimicrobial activity against multidrug resistant organisms was also investigated.

\section{Experimental}

\section{Collection of plant}

Thevetia peruviana leaves were collected from the $T$. peruviana tree (Fig. 1a) located behind the Department of Chemistry, University of Ilorin, Nigeria.

\section{Preparation of extract}

Fresh leaves of T. peruviana were washed thoroughly with double-distilled water (DDW) and then cut into small pieces. Approximately $10 \mathrm{~g}$ of the leaves were then boiled with $100 \mathrm{~mL}$ of DDW for $10 \mathrm{~min}$. The aqueous solution was filtered and stored at $4{ }^{\circ} \mathrm{C}$ until further use (Elemike et al. 2014).

\section{Synthesis of silver nanoparticles}

In a typical reaction procedure, $5 \mathrm{~mL}$ of $T$. peruviana aqueous leaf extract was added to $20 \mathrm{~mL}$ of $1 \mathrm{mM}$ silver nitrate solution. The gradual colour change of the resulting mixture signified the formation of silver nanoparticles. The nanoparticles precipitated out of the reaction medium after $4 \mathrm{~h}$.

\section{Optimization of the synthesis of silver nanoparticles}

The synthesis was carried out at different temperatures (30, 50 and $80^{\circ} \mathrm{C}$ ). To study the optimum time for the synthesis of silver nanoparticles, the reaction mixture was monitored from 0 to $30 \mathrm{~min}$. In addition, the effect of volume was monitored by varying the volume ratio of $\mathrm{AgNO}_{3}$ to $T$. peruviana leaf extract. The concentrations of reacting $\mathrm{AgNO}_{3}$ to $T$. peruviana aqueous leaf extract was ranged from 1 to $5 \mathrm{mM}$. The electronic absorption spectra of the

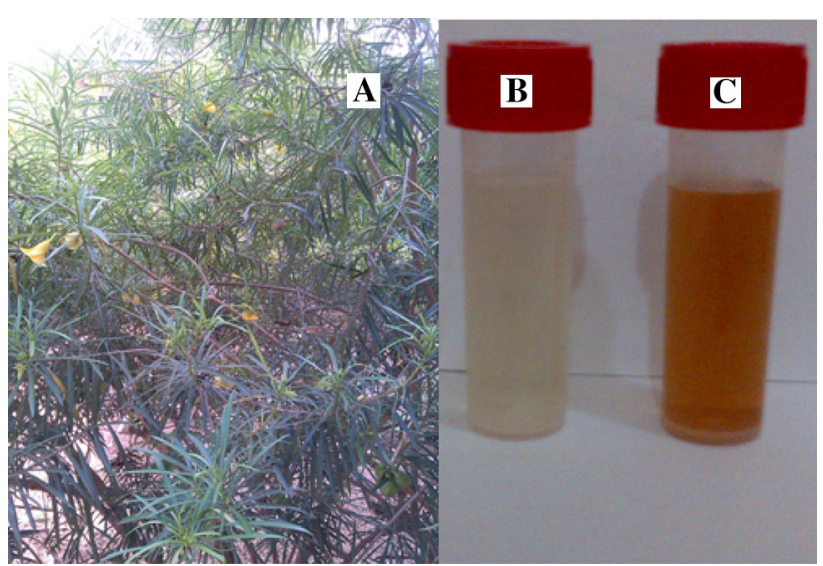

Fig. 1 a Thevetia peruviana plant, b $T$. peruviana aqueous leaf extract, $\mathbf{c}$ TSNP 
silver nanoparticles under each reaction condition were recorded.

\section{Separation and purification of silver nanoparticles}

The nanoparticles solution obtained was purified and separated by repeated centrifugation at $15,000 \mathrm{rpm}$ for $10 \mathrm{~min}$. The centrifugation process was repeated 2-3 times to ensure the removal of any adsorbed substances on the surface of the silver nanoparticles.

\section{Characterization of silver nanoparticles}

The bioreduction of the $\mathrm{Ag}^{+}$to $\mathrm{Ag}^{0}$ was monitored using T60 UV-Visible spectrophotometer. The scanning range employed was 200-900 $\mathrm{nm}$ with a resolution of $1 \mathrm{~nm}$. The functional groups responsible for the synthesis of silver nanoparticles were identified by Shimadzu (8400S) Fourier Transform Infrared using $\mathrm{KBr}$ pellet. The infrared spectrum of the nanoparticles and the aqueous extract was recorded on a FTIR spectrometer. The crystallinity of the silver nanoparticles was examined using X-ray Diffractometer with monochromatic $\mathrm{CuK} \propto \alpha$ radiation $(\theta=1.5406 \AA)$ operating at a voltage of $40 \mathrm{kV}$ and a current of $30 \mathrm{~mA}$ at room temperature. The intensity data for the silver nanoparticles was collected over a $2 \theta$ range of $10^{\circ}-80^{\circ}$. Scanning Electron Microscope (SEM) instrument equipped with an EDX attachment and Transmission Electron Microscope (TEM) were used to characterize the nanoparticles surface morphology and measure the size. Transmission Electron Microscopy (TEM) measurements were performed on a JEOL TEM 1010 transmission electron microscope at $200 \mathrm{kV}$. Carl Zeiss ultra plus field emission electron microscope (FESEM) was used at $5 \mathrm{kV}$ accelerating voltage. Sample was placed on aluminium stabs using carbon tape.

\section{Screening for antimicrobial activities}

Thevetia peruviana synthesized silver nanoparticles (TSNP) was used against multi drug resistant microorganisms (MDRM) which include Escherichia coli, Klebsiella pneumonia, Pseudomonas aeruginosa, Staphylococcus aureus, Bacillus subtilis, Salmonella typhi, Candida albicans, and Aspergillus niger.

Each of the organisms was recovered for testing by subculturing on fresh media. A loopful inoculum of each bacterium was suspended in $5 \mathrm{~mL}$ of nutrient broth and incubated overnight at $37^{\circ} \mathrm{C}$. These overnight cultures were used as inoculums in all the experiments. Nutrient agar, nutrient broth and Potato Dextrose Agar were used, adjusted to $\mathrm{pH} 7$ and sterilized by autoclaving at $15 \mathrm{lbs}$ pressure $\left(121^{\circ} \mathrm{C}\right)$ for $15 \mathrm{~min}$. The PDA was used for
Candida albicans, and Aspergillus niger. The pure cultures of microorganisms were maintained on nutrient agar slant by frequent subculturing. These cultures were stored at $4{ }^{\circ} \mathrm{C}$ for further experiments (Buvaneswari et al. 2011).

The antimicrobial activity was carried out using Agarwell diffusion method (Elemike et al. 2014; Peter et al. 1998). $0.5 \mathrm{~mL}$ each of the seeded broth containing $10^{5} \mathrm{cfu} /$ $\mathrm{mL}$ of the test organisms were incubated on solid nutrient agar plates and spread uniformly with a glass spreader. Two wells were bored in the agar layer of each plate using sterile cork borer of $2 \mathrm{~mm}$ diameter. $0.2 \mathrm{~mL}$ of TSNP solution ( $1 \mathrm{mg} / \mathrm{mL})$ and aqueous extract of $T$. peruviana leaf were introduced in the wells using micropipettes and allowed to diffuse at room temperature for $2 \mathrm{~h}$. The plates were incubated at $37^{\circ} \mathrm{C}$ (bacteria) and $28^{\circ} \mathrm{C}$ (fungal pathogens) for 18-24 h (Ma et al. 2003). After the incubation period, the mean diameters of the zones of inhibition around the wells were recorded and shown in Table 2. The experiments were conducted in triplicates and the average values were recorded for antimicrobial activity.

\section{Results and discussion}

\section{UV-Vis spectral studies}

The bioreduction of the $\mathrm{Ag}^{+}$to $\mathrm{Ag}^{0}$ proceeds gradually after the addition of $T$. peruviana aqueous leaf extract (Fig. 1b) to silver nitrate solution. The bioreduced $\mathrm{Ag}^{0}$ gave reddish-brown coloured solution (Fig. 1c) which is characteristics of silver nanoparticles (Elemike et al. 2014). This indicates the green route to the reduction of silver ions and stabilization of silver nanoparticles produced. The optical properties of metallic nanoparticles arise from a complex electrodynamic effect that is strongly influenced by the surrounding dielectric medium. Light impinging on metallic particles causes optical excitations of their electrons. The principal type of optical excitation that occurs is the collective oscillation of electrons in the valence band of the metal (Peter et al. 2010). The peak intensity of the surface plasmon absorption for TSNP occurred in the optical region of the UV-Visible spectrum at $460 \mathrm{~nm}$. The appearance of surface plasmon resonance (SPR) peak at $460 \mathrm{~nm}$ provides a convenient spectroscopic signature for the formation of silver nanoparticles (Jenkins and Snyder 1996; Bindhu and Umadevi 2014).

\section{Influence of temperature and time}

It is generally accepted that UV-Vis spectroscopy could be used to examine the reduction in size and shape-controlled nanoparticles in aqueous solution (Javed et al. 2011). The graphs (Fig. 2) showed the UV-Vis absorption of silver 

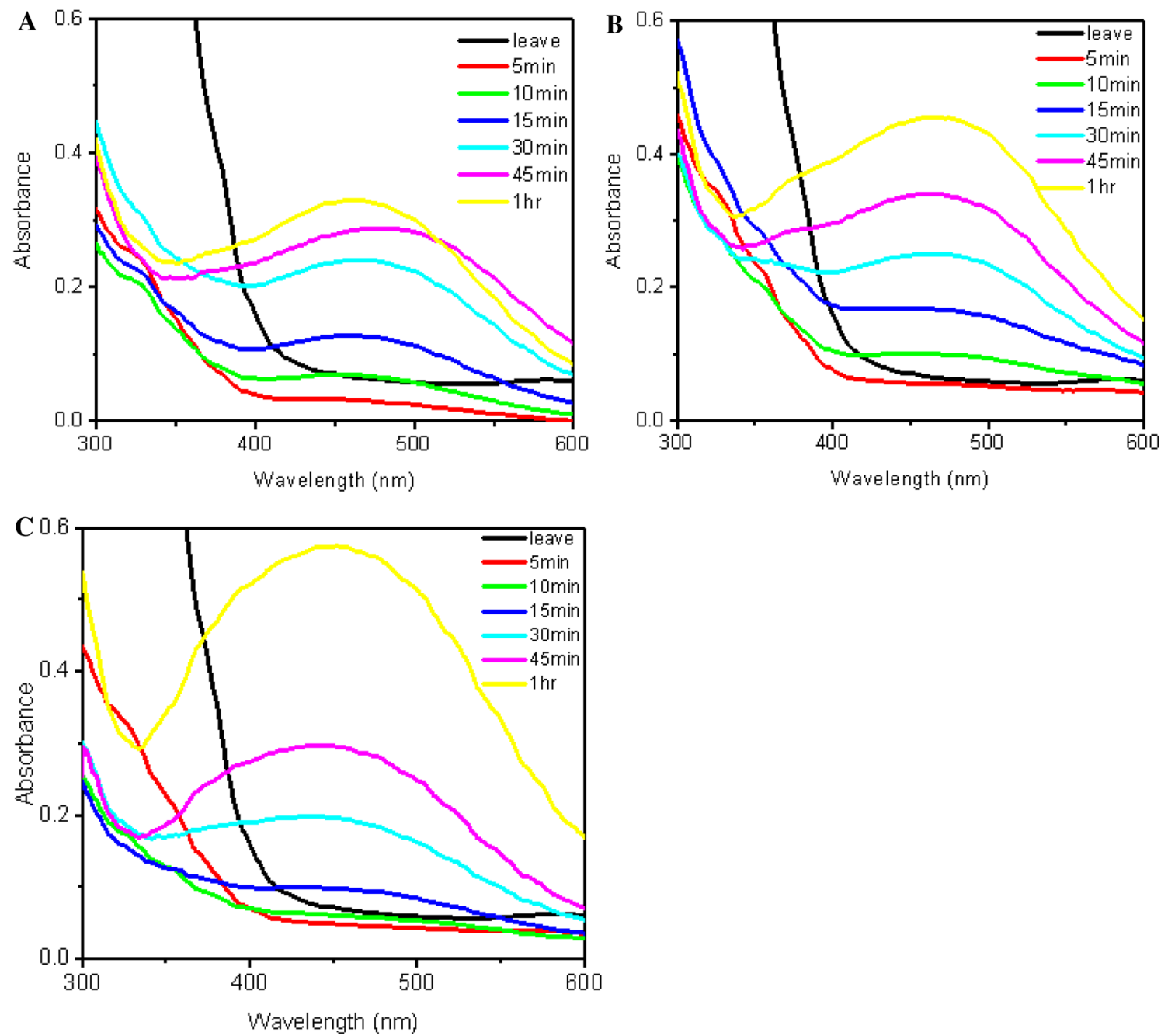

Fig. 2 The UV-Vis absorption spectra for silver nanoparticles synthesized at a $30{ }^{\circ} \mathrm{C}, \mathbf{b} 50{ }^{\circ} \mathrm{C}, \mathbf{c} 80{ }^{\circ} \mathrm{C}$

nanoparticles obtained from $T$. peruviana leaf extract. The spectra were recorded at 30,50 and $80{ }^{\circ} \mathrm{C}$ with varying reaction time. With all the different temperatures used, the colour of the silver nanoparticles changed from light yellow to reddish brown within $15 \mathrm{~min}$. This is characteristic of the nanoparticles due to the excitation of surface plasmon vibrations in the silver nanoparticles synthesized. The reaction was monitored to $1 \mathrm{~h}$ using UV-Visible spectrophotometer. It was observed that the absorption intensity increased with increase in the reaction time. The surface plasmon band of TSNP was at 460, 460 and $440 \mathrm{~nm}$ at 30, 50 , and $80^{\circ} \mathrm{C}$ temperatures, respectively (Fig. 2). This shows that at lower temperatures the plasmon peak showed a bathochromic shift from that observed at $80{ }^{\circ} \mathrm{C}$. This bathochromic shift indicated that the mean diameter of the silver nanoparticles decreased (Bindhu and Umadevi 2014). The formation of silver nanoparticles at $30^{\circ} \mathrm{C}$ underscores the ability of $T$. peruviana aqueous leaf extract to reduce silver ion and stabilize it without employing high temperature. The onset of silver nanoparticles formation was faster at $30{ }^{\circ} \mathrm{C}$ (Fig. 2a) than the synthesis at higher temperatures. It was observed at $10 \mathrm{~min}$. This shows that silver nanoparticles can be synthesized rapidly at $30{ }^{\circ} \mathrm{C}$. The red shifted and narrow shaped surface plasmon resonance (SPR) band indicates the formation of spherical and homogeneous distribution of silver nanoparticles. SEM and TEM images showed that the nanoparticles are agglomerate and spherical in shape. The precipitation of nanospherical crystalline silver particles from the aqueous reaction mixture was observed after $4 \mathrm{~h}$ at all the temperatures used. This suggests that the nanoparticles can be obtained without applying centrifugal force. Although, centrifugation is needed to remove adsorbed biomolecules from the nanoparticles. The precipitation of metallic nanocrystals from aqueous or non-aqueous solutions typically requires the chemical reduction of a metal cation (Peng et al. 2010). We suggest that the fast precipitation of silver nanoparticles from the reaction medium may be due 
to the reductive properties of the polyphenolic moiety present in flavanone glycosides: $(2 R)-$ and $(2 S)-5-O-\beta-\mathrm{D}-$ glucopyranosyl-7, $4^{\prime}$-dihydroxy-3', $5^{\prime}$-dimethoxyflavanone and flavonol glycoside: quercetin $3-O-\{\beta$-D-glucopyranosyl- $(1 \rightarrow 2)$-[ $\alpha$-L-rhamnopyranosyl- $(1 \rightarrow 6)]-\beta$-D-galactopyranoside\} in T. peruviuana leaf (Scheme 1) (Supinya et al. 2002; Ajitha et al. 2015). This is in line with the report of Harekrishna et al. 2009, which suggests the participation of carbonyl, hydroxyl, and amine functional groups in nanoparticles synthesis. The glycosides have been shown to have inhibitory effect against HIV-1 reverse transcriptase and HIV-1 Integrase (Supinya et al. 2002). The optimal reaction time and temperature was achieved at 30 min and $30{ }^{\circ} \mathrm{C}$, respectively.

\section{Influence of silver ion concentration variation}

The UV-Vis spectra obtained at varying silver ion concentration was measured (Fig. 3a). The reaction was carried out at the optimum temperature and time. The intensity increases as the concentration of silver ion increases with the SPR peak for all the different concentrations at $460 \mathrm{~nm}$. The increase in particle size at higher concentrations gave rise to increase in the intensity of the spectrum (Bindhu and Umadevi 2014).

\section{Volume variation}

The influence of change in volume of silver nitrate to $T$. peruviana aqueous leaf extract was investigated (Fig. 3b). The reaction was done at the optimum temperature and time. Different volume ratios ranging from 4:1, 3:2, 2:3 and $1: 4$ of $1 \mathrm{mM}$ silver nitrate to T. peruviana aqueous leaf extract, respectively, were used. From the UV-Vis spectrum (Fig. 3b), it was observed that at 4 parts of $1 \mathrm{mM}$ silver nitrate solution to 1 part of $T$. peruviana aqueous leaf extract (4:1), the leaf extract bioreduced and stabilized the nanoparticles with the plasmon resonance at $460 \mathrm{~nm}$. Other volume ratios, 3:2, 2:3 and 1:4 of $1 \mathrm{mM}$ silver nitrate to $T$. peruviana aqueous leaf extract did not give distinct characteristics SPR for silver nanoparticles at the visible region of the UV-Vis spectrum (Fig. 3b).
For further synthesis of TSNP, the optimal conditions used were $4: 1$ of $1 \mathrm{mM}$ of silver nitrate solution to the leaf extract at $30{ }^{\circ} \mathrm{C}$ for $30 \mathrm{~min}$.

\section{XRD analysis}

$\mathrm{X}$-ray diffraction (XRD) patterns confirmed the crystalline nature of TSNP. Bragg's angles at $37.9^{\circ}, 46.2^{\circ}, 64.3^{\circ}$, $76.6^{\circ}$, which correspond to (111), (200), (220) and (311) crystal reflection planes of the four faces of face centered cubic (fcc) crystal structure of silver (JCPDS data no. 04-0783) were observed (Fig. 4). Reflection planes (111) and (200) were the predominant orientations, while the reflections of (220) and (311) were weak and broad. This trend is in line with the reports of previous workers (Saraschandra and Sivakumar 2014; Ashok et al. 2010; Shashi et al. 2010). The XRD pattern thus clearly illustrates that the silver nanoparticles are crystalline in nature. The extra diffraction peak $(*)$ in the XRD pattern is due to the crystallization of bio-organic phase in the plant extract.

\section{FTIR analysis}

The FTIR spectrum was recorded within the wavenumber of $4000-500 \mathrm{~cm}^{-1}$ region. The FTIR spectrum analysis showed carbonyl groups $(\mathrm{C}=\mathrm{O})$, saturated aliphatic $(-\mathrm{CH})$ and hydroxyl groups $(-\mathrm{OH})$ stretch at wave numbers 1700 , 2930 and $3400 \mathrm{~cm}^{-1}$, respectively (Fig. 5). The biomolecules present in $T$. peruviana aqueous leaf extract possess carbonyl, and glycosidic $\mathrm{OH}$ functional groups. These phytochemicals probably exhibited bifunctional property of reducing and stabilizing the silver nanoparticles. The FTIR spectrum of TSNP showed a lower intensity than that of the leaves extract. The reduction in intensity results from the utilization of the functional groups present in T. peruviana leaf in the synthesis of the silver nanoparticles. The absorption band at $3400 \mathrm{~cm}^{-1}$ can be assigned to the $-\mathrm{OH}$ functional group present in flavanone glycosides; $(2 R)$ - and (2S)-5-O- $\beta$-D-glucopyranosyl-7, $4^{\prime}$-dihydroxy- $3^{\prime}, 5^{\prime}$-dimethoxyflavanone and flavonol glycoside, quercetin 3-O-\{ $\beta$-Dglucopyranosyl-( $1 \rightarrow 2)$-[ $\alpha$-L-rhamnopyranosyl- $(1 \rightarrow 6)]$ $\beta$-D-galactopyranoside $\}$ which is contained in $T$.

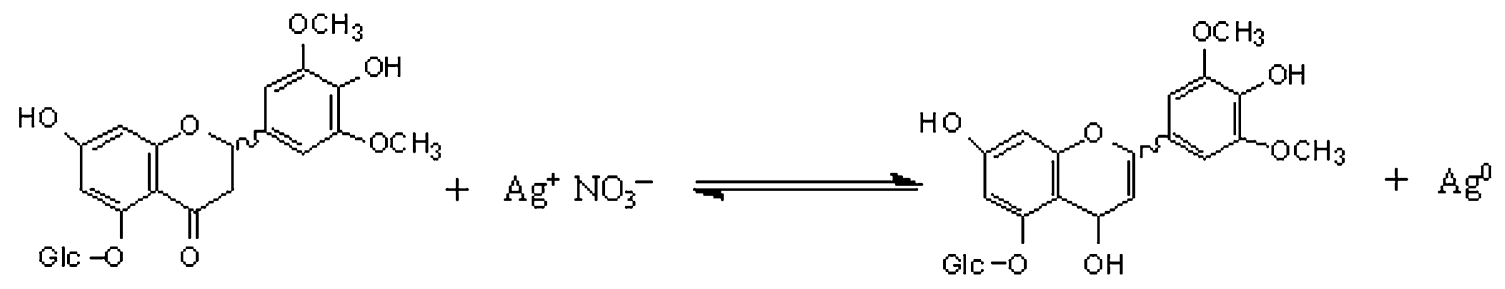

Scheme 1 Possible bioreduction mechanism of silver ion to silver nanoparticles by flavanone glucoside 

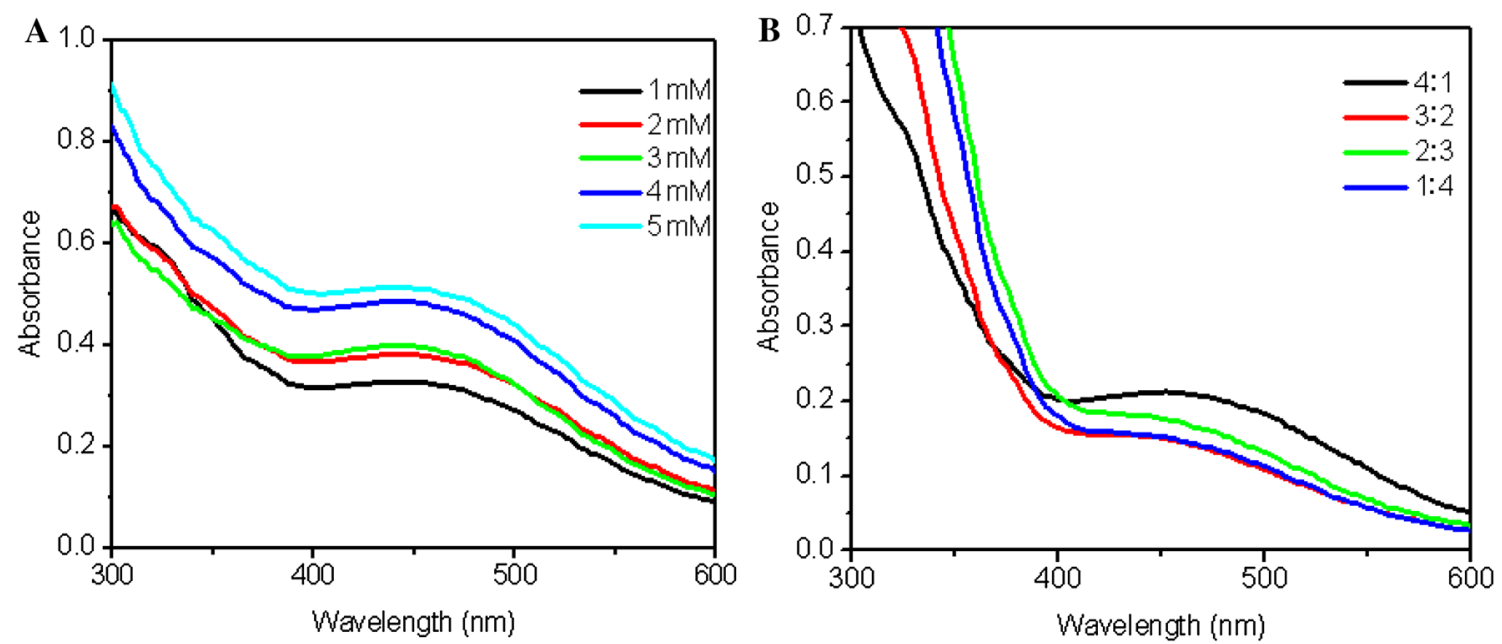

Fig. 3 The UV-Vis absorption spectra for silver nanoparticles synthesized at different $\mathbf{a}$ concentrations and $\mathbf{b}$ volume ratio at $30{ }^{\circ} \mathrm{C}$ for 30 min

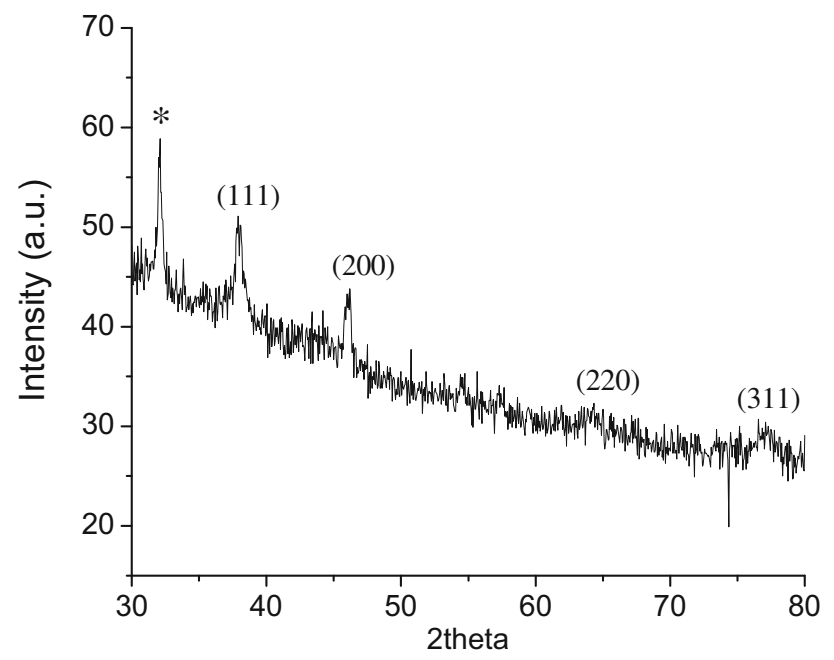

Fig. 4 XRD pattern for T. peruviana aqueous leaves synthesized silver nanoparticles

peruviuana leaf. The $\mathrm{C}=\mathrm{O}$ at $1700 \mathrm{~cm}^{-1}$ can be assumed to originate from the ketonic $\mathrm{C}=\mathrm{O}$ of the flavanone.

\section{SEM and energy dispersive $\mathrm{X}$-ray analysis}

The SEM image showed that the crystalline silver nanoparticles were uniform and aggregates (Fig. 6a). Energy dispersive spectroscopy is used to quantify the chemical composition of nanomaterials (Dada et al. 2015). TSNP showed the highest count per seconds at $3 \mathrm{keV}$, confirming the formation of silver nanoparticles (Fig. 6b). The absorption of metallic silver nanocrystals is generally observed at $3 \mathrm{keV}$ due to surface plasmon resonance (Bindhu and Umadevi 2013). The percentage elemental composition of the TSNP is as shown below (Table 1). The percentage of $\mathrm{O}$ is the smallest, with $\mathrm{C}$ and

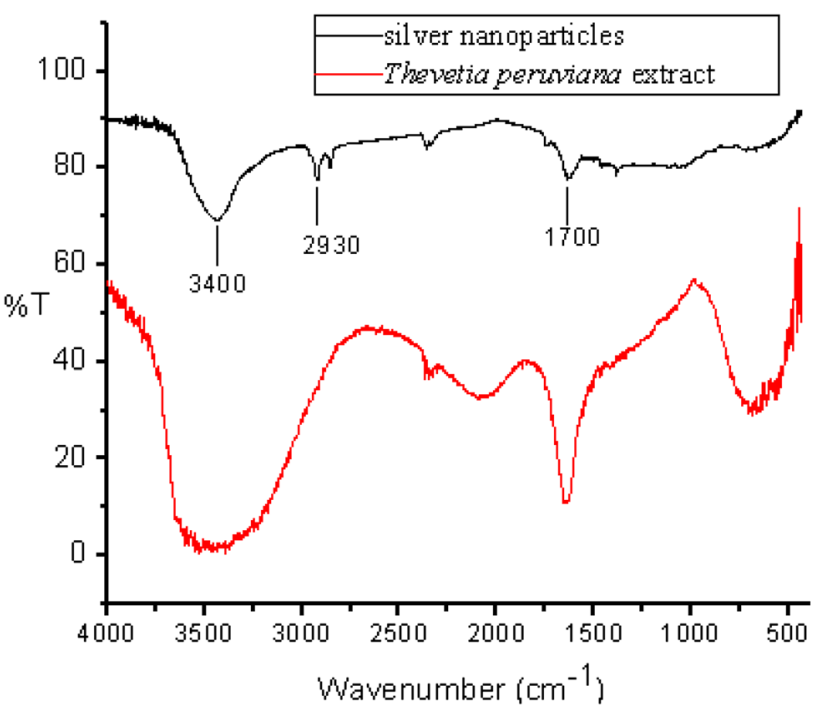

Fig. 5 FTIR spectrum of $T$. peruviana extract and silver nanoparticles

$\mathrm{Cl}$ having high percentage weight. These elements are from the biomolecules that were attached to the silver nanoparticles.

\section{TEM analysis}

TSNP morphology and size were determined from the TEM images. Two different magnifications were employed in the TEM characterization. The silver nanoparticles were spherical in shape. The sizes ranged from 6.4 to $39.4 \mathrm{~nm}$ and the average size was $18.1 \pm 6.4 \mathrm{~nm}, \mathrm{RSD}=35 \%$ (Fig. 6c, d). The Selected Area Electron Diffraction (SAED) showed that the TSNP is crystalline with the spots arising from Bragg reflection (Fig. 6c, inset). Rupiasih et al. (2013) had reported that the size distribution of silver 

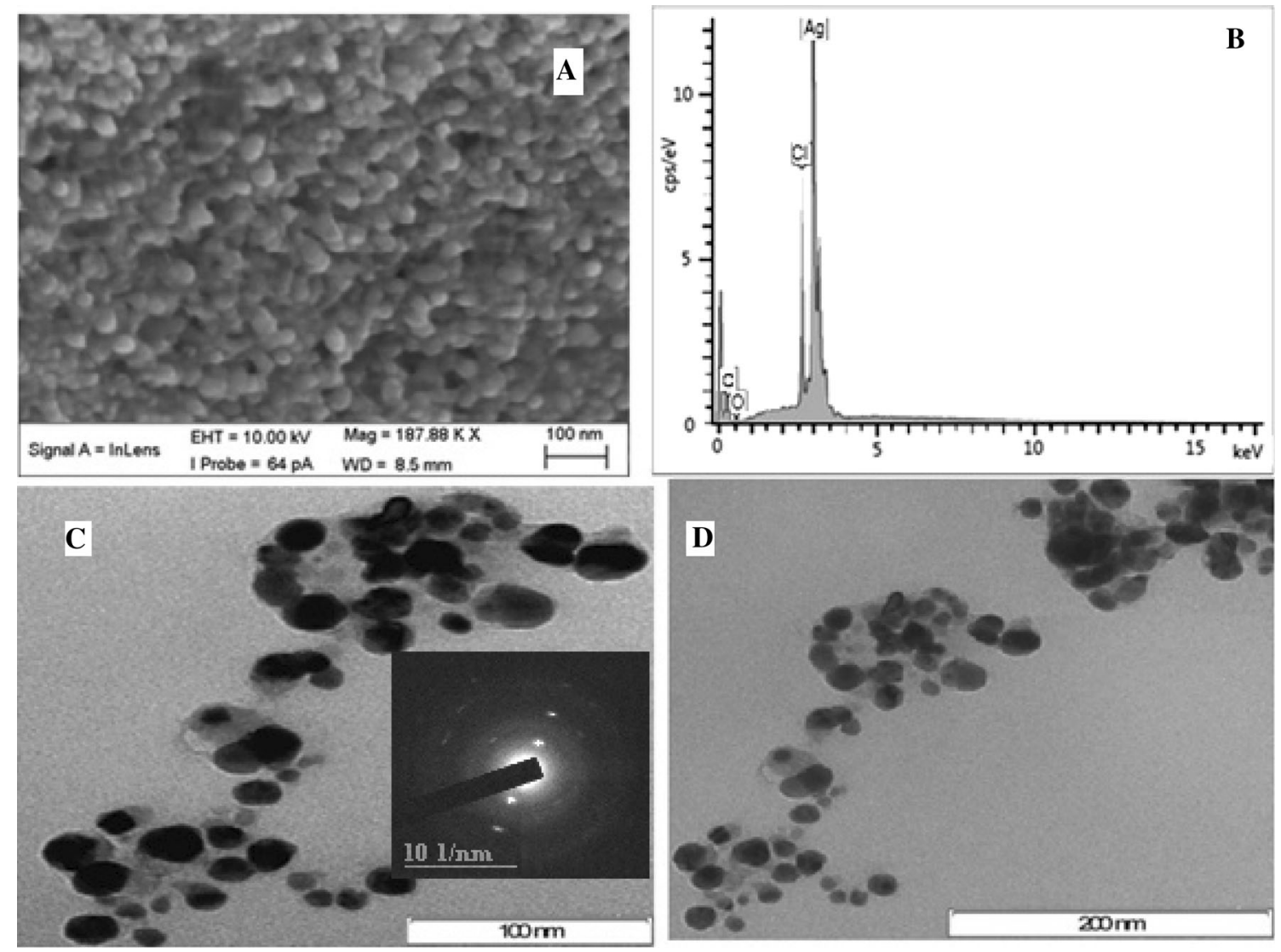

Fig. 6 a SEM image, b EDX spectrum, c TEM image at $100 \mathrm{~nm}$ (inset SAED image of TSNP), d TEM image at $200 \mathrm{~nm}$

Table 1 EDX elemental composition of TSNP

\begin{tabular}{lr}
\hline Elements & \multicolumn{1}{c}{ wt $\%$} \\
\hline $\mathrm{C}$ & 9.09 \\
$\mathrm{O}$ & 1.49 \\
$\mathrm{Cl}$ & 13.54 \\
$\mathrm{Ag}$ & 75.88 \\
Total & 100.00 \\
\hline
\end{tabular}

nanoparticles synthesized using the latex of Thevetia peruviana was between 10 and $30 \mathrm{~nm}$. Elemike et al. (2014) reported the size of silver nanoparticles synthesized using pineapple leaf as $12.4 \mathrm{~nm}$. Recently, Debasis et al. (2015) reported the size of silver nanoparticles synthesized by $F$. benghalensis and A. indica as 85.95 and $90.13 \mathrm{~nm}$, respectively.

\section{Antimicrobial studies}

The result of the antimicrobial studies of TSNP against multi drug resistant microorganisms (MDRM) revealed that the silver nanoparticles showed activity against fungal
Table 2 The zone of inhibition of TSNP against some multidrug resistant microorganisms

\begin{tabular}{ll}
\hline Organisms & Zone of inhibition $(\mathrm{mm})$ \\
\hline Staphylococcus aureus & $20 \pm 2.5$ \\
Pseudomonas aeruginosa & $10 \pm 2.4$ \\
Bacillus subtilis & $11 \pm 0.9$ \\
Klebsiella pneumonia & $15 \pm 1.8$ \\
Escherichia coli & $10 \pm 2.0$ \\
Salmonella typhi & $12 \pm 2.9$ \\
Aspergillus niger & $20 \pm 0.5$ \\
Candida albicans & $20 \pm 1.8$
\end{tabular}

Mean values $\pm \mathrm{SD}$

pathogens and bacteria tested (Table 2; Fig. 7). The plant extract was introduced in the middle of the agar in the plate, but showed no zone of inhibition around it. A. niger and $C$. albicans both showed $20 \mathrm{~mm}$ as their value of inhibition. Both the Gram-positive cocci ( $S$. aureus, B. subtilis) and Gram-negative bacteria ( $P$. aeruginosa, $K$. pneumonia, E. coli, and S. typhi) were susceptible to the influence of the silver nanoparticles. The bactericidal activity of the silver nanoparticles was highest against 


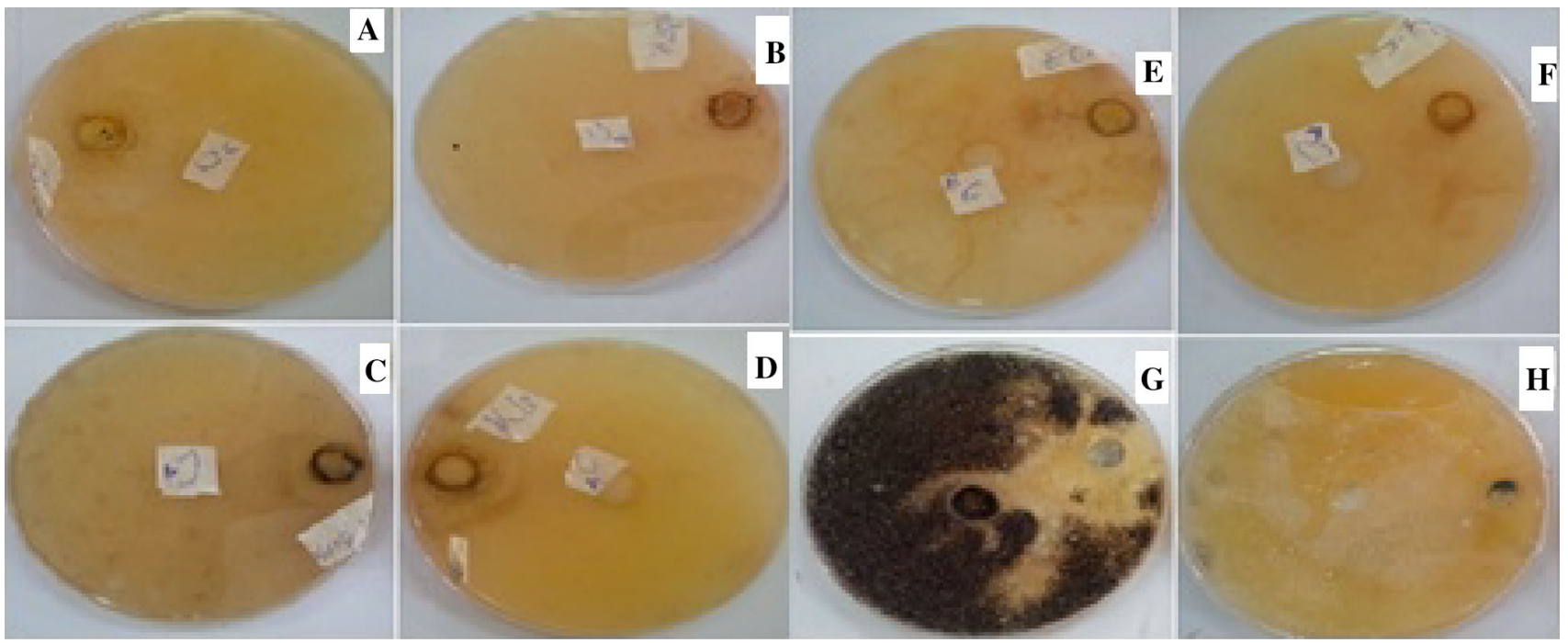

Fig. 7 Antimicrobial activity of silver nanoparticles against multidrug resistant microorganisms. a Staphylococcus aureus, b Pseudomonas aeruginosa, c Bacillus subtilis, d Klebsiella pneumonia, e Escherichia coli, f Salmonella typhi, $\mathbf{g}$ Aspergillus niger, h Candida albicans

Gram positive S. aureus with zone of inhibition of $20 \mathrm{~mm}$. The main component of the cell walls of Gram-positive bacteria is a rigid network composed of three macromolecular concentric shells making it resistant to mechanical rupture, while Gram-negative bacteria have a network that is only one molecule thick, together with up to $25 \%$ (mass) of lipoprotein and lipopolysaccharide (Ma et al. 2003; Olajire et al. 2010). The small size of the silver nanoparticles synthesized in this work enabled the easier penetration into the cell wall of $S$. aureus thereby affecting the cell membrane and finally death of the cell. There is formation of 'pits' on the cell surface, followed by accumulation of the nanoparticles on the cell surface (Sondi and Salopek-Sondi 2004). In addition, the bactericidal activity could be mediated via silver ions released either from colloidal silver nanoparticles in the solution or immobilized nanoparticles (Shekhar et al. 2013). The silver ions then combined with thiol, hydroxyl, and carboxyl group in the cell, deactivate several functions in the cell and damage the cells. Silver nanoparticles combined with respiratory enzyme, protease enzyme and interact with the sulfur and phosphorus of the DNAs of bacteria to cause suffocation, indigestion, inhibition of cell replication, respectively, and thus terminate the microbes (Lokina et al. 2014; Sukumaran and Eldho 2012). The mechanism of antifungal potential has been suggested as the deactivation of sulfhydryl groups of the fungal cell wall, and onward formation of insoluble compounds followed by the disruption of membrane bound enzymes and lipids finally resulting in cell lysis (Ajitha et al. 2015). TSNP has potential against fungal pathogens and bacterias, thereby making it of viable use in the treatment of broad range microorganism infections.

\section{Conclusion}

This work has shown the rapid biosynthesis of silver nanoparticles using the aqueous extract of $T$. peruviana leaf. The silver nanoparticles were characterized using UV-Vis spectrophotometer, XRD, FTIR, SEM, EDX, TEM and SAED. The obtained nanoparticles were highly uniform with average size of $18.1 \mathrm{~nm}$, crystalline and spherical in shape. The functional groups responsible for biosynthesis were also identified. TSNP was found to be smaller than some of the previously reported silver nanoparticles. The efficacy of the synthesized silver nanoparticles against broad spectrum of microorganism was also reported. The potential of $T$. peruviana leaf as a bioresource for green nanosynthesis has been explored. However, further studies to determine the health and environmental impacts of the synthesized silver nanoparticles before its use in biomedicine, is of high importance.

Acknowledgments The authors wish to acknowledge the Vice Chancellor of Federal University Lafia, Nigeria, Prof. Ekanem Ikpi Braide and Dr Mrs Roshila Moodley of the University of KwaZuluNatal, South Africa, for their support and help during the course of this research work.

Open Access This article is distributed under the terms of the Creative Commons Attribution 4.0 International License (http:// creativecommons.org/licenses/by/4.0/), which permits unrestricted use, distribution, and reproduction in any medium, provided you give 
appropriate credit to the original author(s) and the source, provide a link to the Creative Commons license, and indicate if changes were made.

\section{References}

Ajitha B, Reddy YAK, Reddy PS (2015) Biosynthesis of silver nanoparticles using Momordica charantia leaf broth: evaluation of their innate antimicrobial and catalytic activities. J Photochem Photobiol B 146:1-9

Ashok B, Bhagyashree J, Ameeta RK, Smita Z (2010) Banana peel extract mediated synthesis of gold nanoparticles. Colloids Surf B $80: 45-50$

Ashokkumar S, Ravi S, Velmurugan S (2013) Green synthesis of silver nanoparticles from Gloriosa superba L. leaf extract and their catalytic activity. Spectrochim Acta Part A Mol Biomol Spectrosc 115:388-392

Bharani M, Thirunethiran K, Varalakshmi B, Gayathiri G, Priya KL (2011) Synthesis and characterization of silver nano particles from Wrightia tinctoria. Int J Appl Biol Pharm Technol 3:58-63

Bindhu MR, Umadevi M (2013) Synthesis of monodispersed silver nanoparticles using Hibiscus cannabinus leaf extract and its antimicrobial activity. Spectrochim Acta Part A Mole Biomol Spectrosc 101:184-190

Bindhu MR, Umadevi M (2014) Silver and gold nanoparticles for sensor and antibacterial applications. Spectrochim Acta Part A Mol Biomol Spectrosc 128:37-45

Buvaneswari K, Ramamoorthy D, Velanganni J (2011) Preliminary phytochemical and antimicrobial activity studies on the leaves of the Indian plant Thevetia neriifolia Juss. World J Agric Sci 7:659-666

Chandran N, Padmanaban S, Sahadevan R (2012) Green synthesis of silver nanoparticles using datura metel flower extract and evaluation of their antimicrobial activity. Int $\mathrm{J}$ Nanomater Biostruct 2:16-21

Cynthia M, Singaravelu V, Manjusri M, Amar KM (2012) Switchgrass (Panicum virgatum) extract mediated green synthesis of silver nanoparticles. World J Nanosci Eng 2:47-52

Dada OA, Adekola FA, Odebunmi EO (2015) Kinetics and equilibrium models for sorption of $\mathrm{Cu}$ (II) onto a novel manganese nano-adsorbent. J Dispers Sci Technol. doi:10.1080/01932691.2015.1034361

Debasis N, Sarbani A, Pradipta RR, Manisha K, Bismita N (2015) Bark extract mediated green synthesis of silver nanoparticles: evaluation of antimicrobial activity and antiproliferative response against osteosarcoma. Mater Sci Eng C. doi:10.1016/ j.msec.2015.08.022

Dutta AC (1964) Botany for degree students, 5th edn. Oxford University Press, Oxford

Elemike EE, Oseghale CO, Chuku A, Labulo AH, Owoseni MC, Mfon R, Enock OD, Adesuji ET (2014) Evaluation of antibacterial activities of silver nanoparticles green-synthesized using pineapple leaf (Ananas comosus). Micron 57:1-5

Ghassan MS, Wasnaa HM, Thorria RM, Ahmed A, Amir A, AbdulAmir HK, AbuBakar M (2013) Green synthesis, antimicrobial and cytotoxic effects of silver nanoparticles using Eucalyptus chapmaniana leaves extract. Asian Pac J Trop Biomed 3(1):58-63

Haoyan W, Hergen E (2009) From silver nanoparticles to thin films: evolution of microstructure and electrical conduction on glass substrates. J Phys Chem Solids 70:459-465

Harekrishna B, Dipak KB, Gobinda PS, Priyanka S, Santanu P, Ajay M (2009) Green synthesis of silver nanoparticles using seed extract of Jatropha curcas. Colloids Surf A Physicochem Eng Asp 348:212-216
Ibiyemi SA, Fadipe VO, Akinremi OO, Bako SS (2002) Variation in oil composition of Thevetia peruviana juss (Yellow Oleander) fruits seeds. J Appl Sci Environ Manag 6:61-65

Iravani S, Korbekandi H, Mirmohammadi SV, Zolfaghari B (2014) Synthesis of silver nanoparticles: chemical, physical and biological method. Res Pharm Sci 9:385-406

Javed IH, Sunil K, Athar AH, Zaheer K (2011) Silver nanoparticles: preparation, characterization, and kinetics. Adv Mat Lett 2:188-194. doi:10.5185/amlett.2011.1206

Jenkins R, Snyder RL (1996) Introduction to X-ray powder diffractiometry. Wiley, New York 544

Jitendra M, Amla B, Abhijeet S, Madan MS (2014) Phytofabrication of nanoparticles through plant as nanofactories. Adv Nat Sci Nanosci Nanotechnol 5:1-10

Kathiravan V, Ravi S, Ashokkumar S (2014) Synthesis of silver nanoparticles from Melia dubia leaf extract and their in vitro anticancer activity. Spectrochim Acta Part A Mol Biomol Spectrose 130:116-121

Kholoud MM, Abou El-Nour A, Abdulrhman A, Reda AAA (2010) Synthesis and applications of silver nanoparticles. Arab J Chem 3(3): $135-140$

Lokina S, Stephen A, Kaviyarasan V, Arulvasu C, Narayanan V (2014) Cytotoxicity and antimicrobial activities of green synthesized silver nanoparticles. Eur J Med Chem 76:256-263

Ma M, Sun Y, Sun G (2003) Antimicrobial cationic dyes: part 1: synthesis and characterization. Dyes Pigm 58:27-35

Mathuravalli K, Eswara LR (2012) Analysis of phytochemical components and anti-microbial activity of the toxic plant Thevetia Peruviana. Ind J Innov Dev 1:97-101

Mousavand T, Ohara S, Umetsu M, Zhang J, Takami S, Naka T, Adschiri T (2007) Hydrothermal synthesis and in situ surface modification of boehmite nanoparticles in supercritical water. J Supercrit Fluids 40:397-401

Muhammad A, Farooq A, Muhammad R, Saeed AJ, Muhammad AI, Umer R (2012) Green synthesis of silver nanoparticles through reduction with Solanum xanthocarpum L. berry extract: characterization, antimicrobial and urease inhibitory activities against Helicobacter pylori. Int J Mol Sci 13:9923-9941

Naheed A, Seema S, Radheshyam R (2012) Rapid green synthesis of silver and gold nanoparticles using peels of Punica granatum. Adv Mat Lett 3:376-380

Nalawade P, Mukherjee P, Kapoor S (2014) Biosynthesis, characterisation and antibacterial studies of silver nanoparticles using pods extract of Acacia auriculiformis. Spectrochim Acta Part A Mol Biomol Spectrosc 129:121-124

Namita S, Soam P (2014) Green nanoparticles for mosquito control. Sci World J. doi:10.1155/2014/496362

Olajire AA, Akinlabi OO, Oluwafunmilayo TL, Olakunle SI, Mukaram AA (2010) Antimicrobial properties of 4-Carboxyl2, 6-dinitrophenylazohydroxynaphthalenes. Afr J Microbiol Res 4:2444-2450

Oluwaniyi OO, Samuel AI (2007) African extractability of Thevetia peruviana glycosides with alcohol mixture. J Biotechnol 6:2166-2170

Peng H, Jing L, Zhiming L, Hengyao H, Kan W, Guo G, Rong H, Daxiang C (2010) A general strategy for metallic nanocrystals synthesis in organic medium. Chem Commun 46:4800-4802. doi:10.1039/C0CC00307G

Peter S, Tinto WF, Mclean S, Reynolds WF, Yu M (1998) Cassane diterpenes from Caesalpinia bonducella. Phytochemistry 47:1153-1155

Peter A, Tina O, Jonathan R, Mark W, Frase A, Michael H (2010) Shriver and Atkins' inorganic chemistry. W. H. Freeman and Company, New York $\mathbf{6 5 7}$

Rajakumar G, Abdul Rahuman A (2011) Larvicidal activity of synthesized silver nanoparticles using Eclipta prostrata leaf 
extract against filariasis and malaria vectors. Acta Trop 118:196-203

Raju V, Ramar T, Krishnasamy M, Palani G, Krishnasamy K, Soundarapandian K (2012) Green biosynthesis of silver nanoparticles from Annona squamosa leaf extract and its in vitro cytotoxic effect on MCF-7 cells. Process Biochem 47:2405-2410

Ravi SS, Christena LR, SaiSubramanian N, Anthony SP (2013) Green synthesized silver nanoparticles for selective colorimetric sensing of $\mathrm{Hg}^{2+}$ in aqueous solution at wide $\mathrm{pH}$ range. Analyst 138:4370-4377

Rupiasih NN, Avinash A, Suresh G, Vidyasagar PB (2013) Green synthesis of silver nanoparticles using latex extract of Thevetia peruviana: a novel approach towards poisonous plant utilization. J Phys Conf Ser 423:1-8

Saraschandra N, Sivakumar A (2014) Eco-friendly synthesis of silver and gold nanoparticles with enhanced bactericidal activity and study of silver catalyzed reduction of 4-nitrophenol. Spectrochim Acta Part A Mol Biomol Spectrosc 128:357-362

Satyavani K, Ramanathan T, Gurudeeban S (2011) Green synthesis of silver nanoparticles by using stem derived callus extract of bitter apple (Citrullus colocynthis). Dig J Nanomater Biostruct 6:1019-1024

Shashi PD, Manu L, Mika S (2010) Tansy fruit mediated greener synthesis of silver and gold nanoparticles. Process Biochem 45:1065-1071

Shekhar A, Soumyo M, Suparna M (2013) Immobilized silver nanoparticles enhance contact killing and show highest efficacy: elucidation of the mechanism of bactericidal action of silver. Nanoscale 5:7328-7340

Silva-de-Hoyos LE, Sánchez-Mendieta V, Rico-Moctezuma A, Vilchis-Nestor AR, Camacho-López MA, Avalos-Borja M (2012) Silver nanoparticles biosynthesized using Opuntia ficus aqueous extract. Superficies y Vacío 25:31-35

Sondi I, Salopek-Sondi B (2004) Silver nanoparticles as antimicrobial agent: a case study on E. coli as a model for Gram-negative bacteria. J Colloid Interface Sci 275:177-182

Sukumaran P, Eldho KP (2012) Silver nanoparticles: mechanism of antimicrobial action, synthesis, medical applications, and toxicity effects. Int Nano Lett 2:32-42

Supinya T, Norio N, Masao H, Tamio F, Tanomjit S (2002) Flavanone and flavonol glycosides from the leaves of Thevetia peruviana and their HIV-1 reverse transcriptase and HIV-1 integrase inhibitory activities. Chem Pharm Bull 50:630-635

Swarnalatha L, Christina R, Shruti R, Payas B (2012) Evaluation of invitro antidiabetic activity of Sphaeranthus amaranthoides silver nanoparticles. Int J Nanomater Biostruct 2:25-29

Vinod KV, Anbarasan S, Lawrence RC, Nagarajan S, Savarimuthu PA (2014) Bio-functionalized silver nanoparticles for selective colorimetric sensing of toxic metal ions and antimicrobial studies. Spectrochim Acta Part A Mol Biomol Spectrosc 129:35-42

Xia YN, Halas NJ (2005) Shape-controlled synthesis and surface plasmonic properties of metallic nanostructures. MRS Bull 30:338-344 